\title{
Light penetration in seawater polluted by dispersed oil: results of radiative transfer modelling
}

\author{
K. Haule \\ k.haule@wm.am.gdynia.pl
}

\section{Darecki}

\section{H. Toczek}

\author{
Gdynia Maritime University, Department of Physics, Gdynia, 81-225, Poland
}

Institute of Oceanology of Polish Academy of Sciences, Sopot, 81-712, Poland

The downwelling light in seawater is shaped by natural seawater constituents as well as by some external substances which can occur locally and temporally. In this study we focused on dispersed oil droplets which can be found in seawater after an oil spill or in the consequence of intensive shipping, oil extraction and transportation. We applied our modified radiative transfer model based on Monte Carlo code to evaluate the magnitude of potential influence of dispersed oil droplets on the downwelling irradiance and the depth of the euphotic zone. Our model was validated on the basis of in situ measurements for natural (unpolluted) seawater in the Southern Baltic Sea, resulting in less than $5 \%$ uncertainty. The optical properties of dispersed Petrobaltic crude oil were calculated on the basis of Mie theory and involved into radiative transfer model. We found that the changes in downwelling light caused by dispersed oil depend on several factors such as oil droplet concentration, size distribution, and the penetration depth (i.e. vertical range of oil droplets occurrence below sea surface). Petrobaltic oil droplets of submicron sizes and penetration depth of $5 \mathrm{~m}$ showed a potentially detectable reduction in the depth of the euphotic zone of $5.5 \%$ at the concentration of only $10 \mathrm{ppb}$. Micrometer-sized droplets needed 10 times higher concentration to give a similar effect. Our radiative transfer model provided data to analyse and discuss the influence of each factor separately. This study contributes to the understanding of the change in visible light penetration in seawater affected by dispersed oil.

[DOI: http://dx.doi.org/10.2971/jeos.2015.15052]

Keywords: Oil pollution, dispersed oil, droplet size distribution, radiative transfer, downwelling irradiance

\section{INTRODUCTION}

The processes of attenuation of visible light in seawater have been studied since the development of modern oceanography in the $20^{\text {th }}$ century in order to provide understanding of primary production of the oceans and marine ecosystem dynamics [1, 2]. Many studies have demonstrated that the penetration of solar visible light in the upper layer of the ocean plays an important role in heat transfer and sea surface temperature [3]-[5]. Light penetration into seawater depends on local seawater composition of various dissolved and suspended materials $[6,7]$. It is described by the spectral depthdependence of downwelling irradiance $E_{d}(z, \lambda)$ [8] or diffuse attenuation coefficient [9]. Spectral downwelling plane irradiance, considered in this study, is defined as the energy of photons headed in downward directions in a time unit per unit surface and unit wavelength $\left[\mathrm{Wm}^{-2} \mathrm{~nm}^{-1}\right][10]$ :

$$
E_{d}(z, \lambda)=\frac{\Delta Q(z, \lambda)}{\Delta t \Delta A \Delta \lambda}
$$

where $\Delta Q(z, \lambda)$ is the radiant energy measured within the time interval $\Delta \mathrm{t}$ at the depth $z$ below sea surface, $\Delta \mathrm{A}$ is the area of detector's diffusing surface and $\Delta \lambda$ is the wavelength interval (centered on wavelength $\lambda$ ).

Another quantity significant for light field analyses in seawater is the depth of the euphotic zone, $z_{1 \%}$. It reflects the depth where the visible light $(400-700 \mathrm{~nm})$ drops to $1 \%$ of its surface value [11]. Euphotic zone depth has been incorporated into global or basin scale remote sensing algorithms and it has become an important product of many biogeochemical studies [12].

Natural decrease of the downwelling light below sea surface is caused by light absorption and scattering processes of seawater constituents. Relationships between light attenuation and concentration of different seawater constituents have been precisely investigated for the purpose of water quality monitoring and management. The most numerous studies focus on phytoplankton biomass [13]-[15] including different algae species as cyanobacteria [16]. Moreover, other relationships between light attenuation and seawater constituents have been studied locally, e.g., colour dissolved organic matter [17], mineral particles [18, 19], or even air bubbles [20]. However, there is very poor knowledge available considering the influence of external substances that can occur accidentally in seawater, such as dispersed petroleum derivatives.

Nowadays oil droplets become quite common constituent of some closed water basins (such as the Baltic Sea), estuaries and routes of intensive shipping or oil extraction and transportation [21, 22]. Moreover, dispersed oil stays in seawater 
for days to month after oil spill [23, 24]. When oil droplets occur in the marine environment, they become additional absorbents and scattering centres affecting light penetration in the water body, and in the consequence - photosynthesis, primary productivity and other biogeochemical processes.

In this study we have modelled and evaluated the possible influence of dispersed Petrobaltic crude oil on the downwelling irradiance and the euphotic zone depth within the water body, taking into account different droplet size distributions, different oil concentrations, and different depths of oil droplets occurrence below sea surface (hereafter referred to as "oil penetration depths").

\section{MATERIAL AND METHODS}

\subsection{Optical properties of natural seawater}

Inherent optical properties (IOPs) of natural seawater were measured in the Southern Baltic Sea at a coastal station L4 (N 54.8, E 17.5) on 25 $5^{\text {th }}$ May 2012. These measurements included spectral absorption $\mathrm{a}(\lambda)$ and attenuation $\mathrm{c}(\lambda)$ coefficients, and were performed using a flow-through absorptionattenuation meter (AC-9, WetLabs; see Appendix A). They represent typical values for case 2 waters with chlorophyll a concentration of $0.73 \mathrm{mg} \cdot \mathrm{m}^{-3}$.

In order to determine the scattering phase function for natural seawater we run a set of radiative transfer (RT) simulations using our model described in [25] with different Fournier-Forand (F-F) phase functions parameterized by different backscattering ratios, $b_{b} / b$ (see $\left.[26,27]\right)$. We compared the remote sensing reflectance $\left(R_{r s}\right)$ from the model with in situ measurement performed by a set of Ramses Trios devices. The $R_{r s}$ has been calculated as a ratio of upwelling radiance, $L_{u}$, measured just below the sea surface (a modified radiometer with narrower diameter has been mounted on the special float positioning kit 2-5 cm below the sea surface) and downwelling irradiance, $E_{d}$, measured on the radiometer mounted on the deck. All measurements have been carried out simultaneously to the IOPs measurements at the station L4. Then the F-F functions that resulted in the best fit between the $R_{r s}$ modelled and measured in situ were chosen for further analysis.

\subsection{Optical properties of seawater polluted by dispersed oil}

In our study we considered two kinds of Petrobaltic light crude oil dispersions characterized by different droplet size distributions. We assumed that crude oil dispersed in marine environment presents most commonly a log-normal size distribution [28]-[30]. We applied the formula given by Jonasz and Fournier [31]:

$$
n(d)=\frac{N}{\sqrt{2 \pi} \sigma d_{0} \exp \left(\frac{1}{2} \sigma^{2}\right)} \exp \left[-\frac{\left(\ln d-\ln d_{0}\right)^{2}}{2 \sigma^{2}}\right],
$$

where $d$ is the droplet diameter (considered in the range of $0.01-100 \mu \mathrm{m}), d_{0}$ is the peak diameter of the size distribution, $\sigma$ is the width parameter of the log-normal size distribution, and $N$ is the total number of oil particles in $1 \mathrm{~m}^{3}$ of seawater.

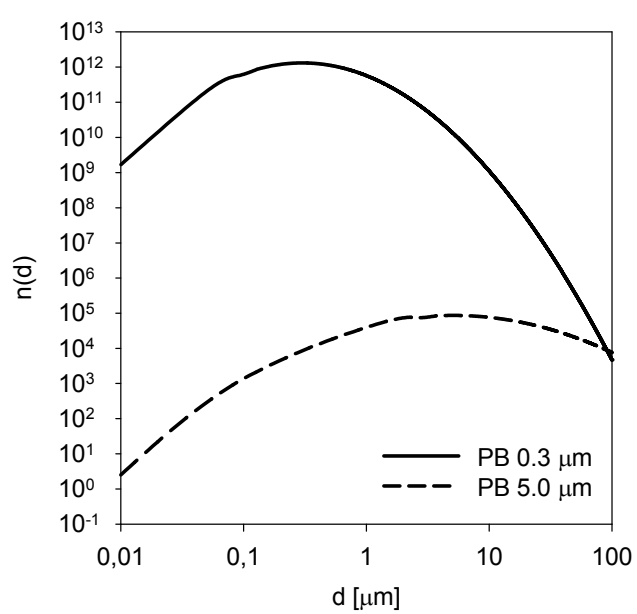

FIG. 1 Two Petrobaltic (PB) oil droplet size distributions characterized by peak diameters of $0.3 \mu \mathrm{m}$ (solid line) and $5.0 \mu \mathrm{m}$ (dashed line).

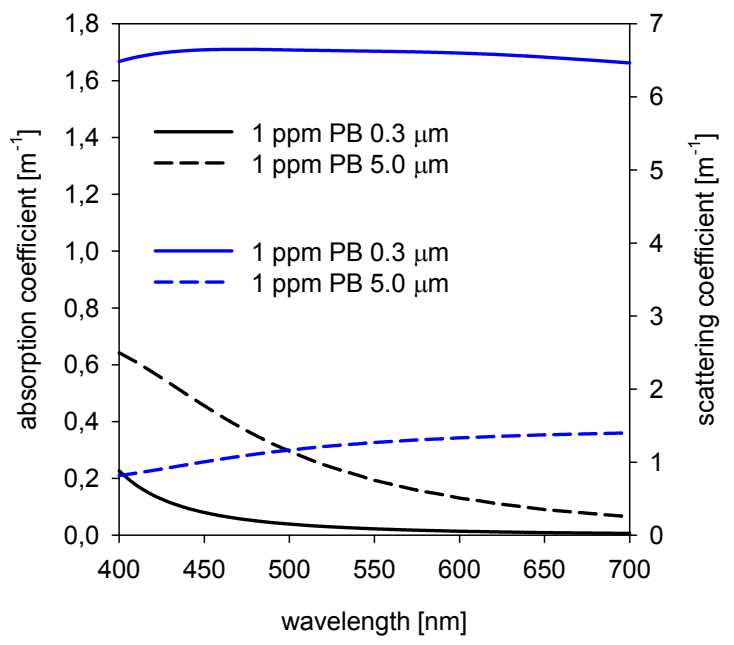

FIG. 2 Spectral absorption (black lines) and scattering (blue lines) coefficients for two Petrobaltic oil dispersions: characterized by size distribution peak diameter of $0.3 \mu \mathrm{m}$ (solid lines) and of $5.0 \mu \mathrm{m}$ (dashed lines).

Parameter $\sigma$ was approximated on the basis of experimentally measured size distributions [32]. In this study we present the results obtained for two oil dispersions: one characterized by peak diameter of $0.3 \mu \mathrm{m}$ (representing very small droplets, and hereafter referred to as "submicron oil droplets"), and another characterized by peak diameter of $5.0 \mu \mathrm{m}$ (representing medium sized droplets, and hereafter referred to as "micrometer-sized droplets") (Figure 1). Some previous studies showed that micrometer-sized oil droplets are present from hours to days in the regions affected by extent oil spills $[24,33]$, while submicron oil droplets form stable emulsions, lasting in seawater from days to months [34].

After choosing oil droplet size distributions we applied Mie calculations, as described by Bohren and Huffman [35], to obtain the IOPs for both dispersions. Complex refractive index for Petrobaltic crude oil was taken from [32]. The scattering angle resolution for phase function calculations was varying from $0.05 \mathrm{deg}$ for small scattering angles to $2 \mathrm{deg}$ for large scattering angles. The results of Mie calculations are shown in the Figure 2 (spectral absorption and scattering coefficients) and Figure 3 (angular phase functions for $555 \mathrm{~nm}$ ). Visible light absorption is much lower (3 to 10 times) for submicron oil droplets than for micrometer-sized ones. On the contrary, 


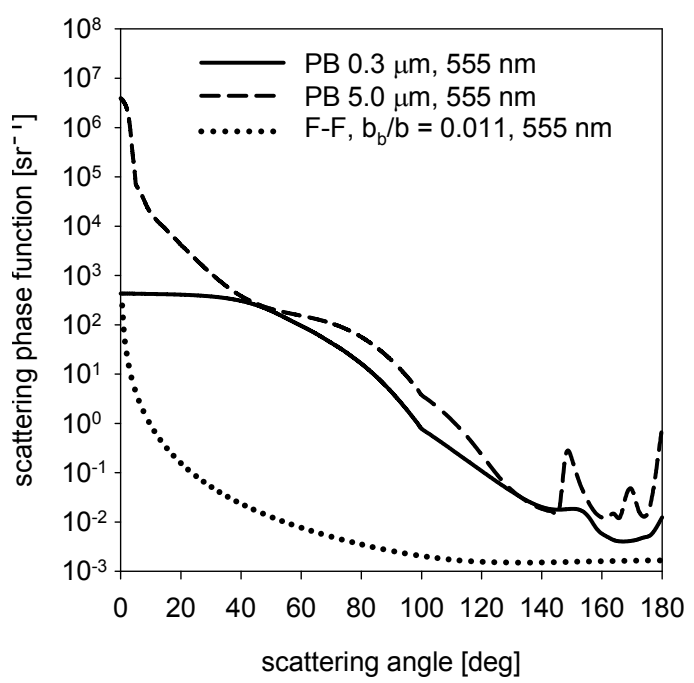

FIG. 3 Angular dependence of scattering phase function at $555 \mathrm{~nm}$ for two oil dispersions: characterized by size distribution peak diameter of $0.3 \mu \mathrm{m}$ (solid line) and of $5.0 \mu \mathrm{m}$ (dashed line). Dotted line represents the F-F phase function for natural seawater (station L4) at $555 \mathrm{~nm}$ parametrized by backscatter ratio $b_{b} / b=0.011$.

scattering in the same spectral region is significantly higher ( 5 to 8 times) for submicron droplets. The analysis of the shape of angular phase function dependence (see Figure 3) indicates that micrometer-sized oil droplets scatter mostly in forward directions (forward scattering is about 7-8 orders of magnitude more probable than backscattering), while submicron oil droplets tend to scatter more symmetrically (showing 4-5 orders of magnitude difference between the probability of forward and backscattering).

\subsection{Radiative transfer simulation}

For radiative transfer modelling we applied our previously described model based on Monte Carlo code [25, 36]. The boundary conditions were chosen as follows: $10 \%$ sky overcast, actual sun elevation (zenith angle) of $58^{\circ}$, wind speed of $5 \mathrm{~ms}^{-1}$, actual seabed at $11 \mathrm{~m}$, lambertian bottom reflectance of $10 \%$ including $2 \%$ of specular reflection and $8 \%$ of diffuse reflection. Oil dispersion penetration depth (i.e. the vertical range of oil droplets occurrence below sea surface) was set from 1 to $5 \mathrm{~m}$, and oil concentrations varied from $10 \mathrm{ppb}$ to $5 \mathrm{ppm}$. As a result of numerous runs of RT simulations we obtained the depth-dependence of downwelling irradiance for natural seawater (station L4) and seawater virtually polluted by previously described dispersions of Petrobaltic crude oil. The euphotic zone depth was calculated as the depth where the downwelling irradiance $E_{d}(555)$ drops below $1 \%$ of its surface value.

\section{RADIATIVE TRANSFER MODELLING RESULTS AND DISCUSSION}

In this section we present the results of radiative transfer modelling for natural seawater and seawater polluted by different oil dispersions described in the Subsection 2.2. Natural seawater is represented by the coastal station L4 in the Southern Baltic Sea with the IOPs typical for spring-summer season (see Appendix A).

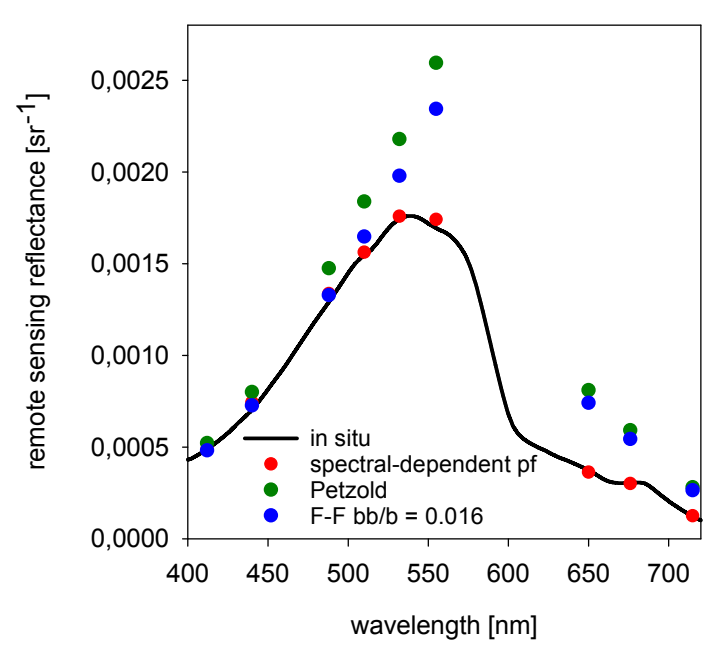

FIG. 4 Remote sensing reflectance measured in situ (solid line) and modelled (dots) on the basis of AC-9 data and different scattering phase functions.

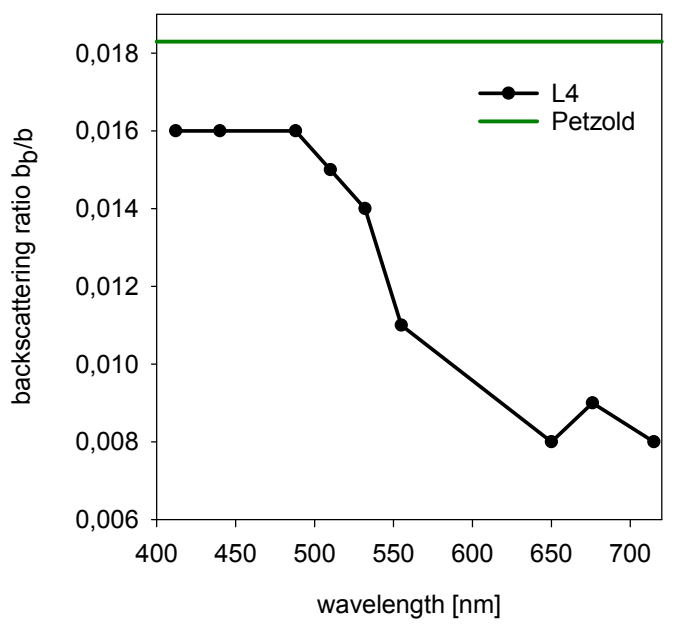

FIG. 5 Backscattering ratios representing the best fit between measured and modelled $R_{r s}$ for the station L4 (N 54.8, E 17.5) in the Southern Baltic Sea; green line represents the backscattering ratio for Petzold phase function commonly used in ocean modelling.

\subsection{Wavelength-dependent scattering phase function}

In our study we took into account the wavelengthdependence of scattering phase function, which is rarely included in radiative transfer studies, despite it seems to be significant, especially in optically complex water basins [37]. We compared the remote sensing reflectance measured in situ and modelled using different F-F functions for each wavelength (Figure 4). Then the best fit was chosen for further analysis.

The spectral-dependence of scattering phase function implies the significance of backscatter spectral variability in case 2 waters. Spectral dependence of the $b_{b} / b$ ratio is shown in the Figure 5. Commonly used Petzold phase function [38] which has a backscattering ratio $b_{b} / b=0.0183$, did not give satisfying results in RT modelling (see the green dots in Figure 4 and the green line in Figure 5), as in the recent studies by Freda and Piskozub [39], and Freda [37]. The inclusion of spectraldependent phase function in RT analysis resulted in the model uncertainty of less than $5 \%$. 


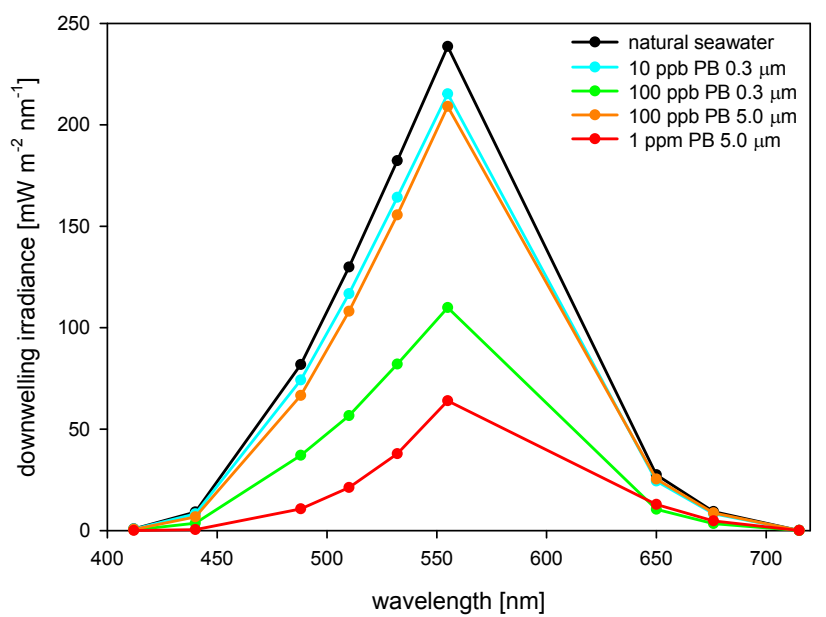

FIG. 6 Spectral downwelling irradiance at $5 \mathrm{~m}$ depth modelled for seawater polluted by Petrobaltic oil dispersions of droplet size distributions characterized by peak diameter $0.3 \mu \mathrm{m}$ and $5.0 \mu \mathrm{m}$ and different oil penetration depths.

\section{downwelling irradiance at $555 \mathrm{~nm}$ $\left[\mathrm{mW} \mathrm{m}^{-2} \mathrm{~nm}^{-1}\right.$ ]}

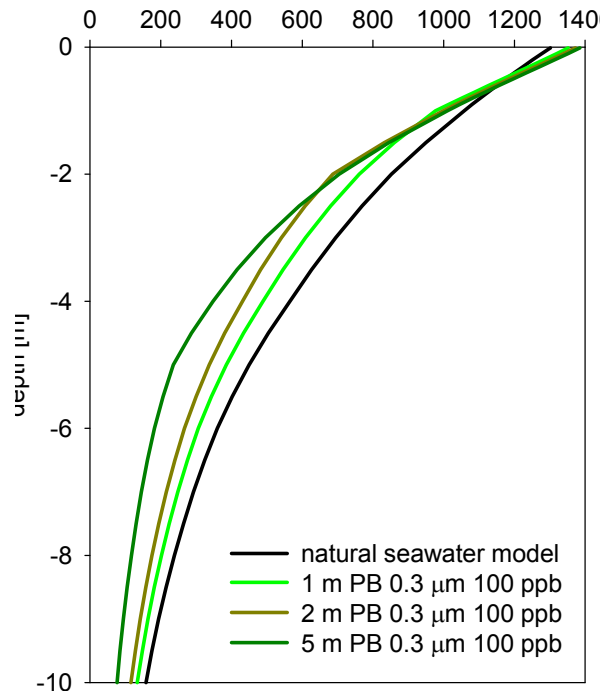

downwelling irradiance at $555 \mathrm{~nm}$ $\left[\mathrm{mW} \mathrm{m}^{-2} \mathrm{~nm}^{-1}\right.$ ]

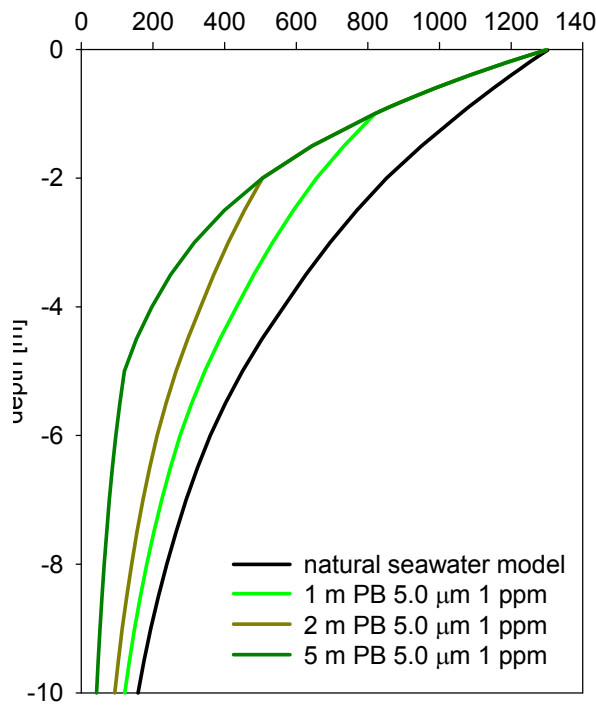

FIC. 7 The influence of oil penetration depth on downwelling irradiance modelled for seawater polluted by Petrobaltic oil dispersions of droplet size distributions characterized by peak diameter $0.3 \mu \mathrm{m}$ (top graph) and $5.0 \mu \mathrm{m}$ (bottom graph).

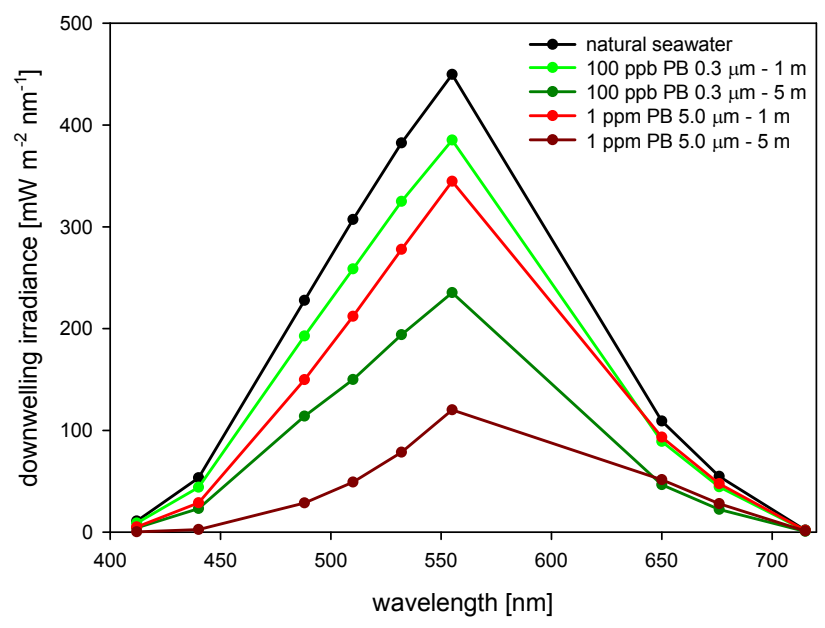

FIG. 8 Spectral downwelling irradiance at $8 \mathrm{~m}$ depth modelled for seawater polluted by different concentrations of Petrobaltic oil dispersions of droplet size distributions characterized by peak diameter $0.3 \mu \mathrm{m}$ and $5.0 \mu \mathrm{m}$.

\subsection{Downwelling irradiance - the influence of oil penetration depth}

Petrobaltic oil droplets when present in seawater tend to decrease the downwelling irradiance $\mathrm{E}_{d}$ in the visible spectral range. In Figure 6 we show spectral dependence of $E_{d}$ at $5 \mathrm{~m}$ depth below sea surface for two considered oil dispersions and two different oil penetration depths. $\mathrm{E}_{d}$ in central bands (corresponding to the green spectral region) was the most affected by the presence of oil, and therefore in the Figures 7 and 9 we present the results for $555 \mathrm{~nm}$. What is interesting, submicron oil droplets caused an increase in the downwelling irradiance just below the water surface, in comparison to the natural (unpolluted) seawater, usually up to $0.5 \mathrm{~m}$ depth. This increase varied in our study from $4-6 \%$ at the oil droplet concentration of $100 \mathrm{ppb}$ to $26-30 \%$ at the concentration of $1 \mathrm{ppm}$. On the contrary, micrometer-sized oil droplets, did not show any increase in the downwelling irradiance within the water body.

The influence of oil penetration depth on the decrease of downwelling irradiance depends on oil droplet concentration and size distribution (see Figure 7). 100 ppm of submicron oil droplets which reached $1 \mathrm{~m}$ below sea surface caused a decrease in the downwelling light of $48 \%$ at $5 \mathrm{~m}$ below sea surface and $52 \%$ at $10 \mathrm{~m}$ below sea surface. The same oil concentration and penetration depth of micrometer-sized droplets caused a decrease in $\mathrm{E}_{d}$ of $12 \%$ at 5-10 m below sea surface. The increase of oil droplet concentration to $1 \mathrm{ppm}$ enhanced the effect of $\mathrm{E}_{d}$ drop to $98 \%$ for submicron oil droplets at $5-10 \mathrm{~m}$ below sea surface, and to $73 \%$ for micrometer-sized oil droplets at 5-10 m below sea surface. Further increase of oil droplet concentration caused the downwelling light to $99 \%$ decrease at shallower depths in the water.

\subsection{Downwelling irradiance - the influence of oil concentration}

In Figure 8 we show spectral dependence of $E_{d}$ at $8 \mathrm{~m}$ depth below sea surface for different concentrations of considered oil dispersions. The impact of oil droplet concentration on the decrease of downwelling light within seawater depends 


\begin{tabular}{|c|ccc|ccc|ccc|ccc|}
\hline & \multicolumn{4}{|c|}{ Petrobaltic $0.3 \mu \mathrm{m}$} & \multicolumn{4}{c|}{ Petrobaltic $0.5 \mu \mathrm{m}$} \\
\cline { 2 - 13 } natural seawater & $1 \mathrm{~m}$ of oil penetration & \multicolumn{5}{|c}{$\mathrm{m}$ of oil penetration } & \multicolumn{1}{c|}{$\mathrm{m}$ of oil penetration } & $5 \mathrm{~m}$ of oil penetration \\
\cline { 2 - 13 } & 10 & 100 & 1 & 10 & 100 & 1 & 100 & 1 & 5 & 100 & 1 & 5 \\
& $\mathrm{ppb}$ & $\mathrm{ppb}$ & $\mathrm{ppm}$ & $\mathrm{ppb}$ & $\mathrm{ppb}$ & $\mathrm{ppm}$ & $\mathrm{ppb}$ & $\mathrm{ppm}$ & $\mathrm{ppm}$ & $\mathrm{ppb}$ & $\mathrm{ppm}$ & $\mathrm{ppm}$ \\
\hline 21.7 & 21.4 & 19.6 & 5.0 & 20.5 & 14.9 & 5.0 & 21.5 & 19.5 & 13.1 & 20.2 & 12.2 & 3.5 \\
\hline
\end{tabular}

TABLE 1 The influence of dispersed oil on the depth of the euphotic zone [m] at $555 \mathrm{~nm}$ (station L4).

mainly on droplet penetration depth and their size distribution (see Figure 9). Submicron oil droplets, when present in the $5 \mathrm{~m}$ water layer, caused small but noticeable $E_{d}$ decrease starting from the concentration of $10 \mathrm{ppb}(8 \%$ at $5 \mathrm{~m}$ and $10 \%$ at $10 \mathrm{~m}$ ), while micrometer-sized droplets needed 10 times higher concentration to produce a similar effect $(12 \%$ at 5-10 m). The increase of submicron droplet concentration resulted in $48 \% \mathrm{E}_{d}$ decrease at $5 \mathrm{~m}$ below sea surface and $52 \%$ $\mathrm{E}_{d}$ decrease at $10 \mathrm{~m}$ depth for $100 \mathrm{ppb}$. Finally, the decrease of the downwelling light reached $98 \%$ at $5-10 \mathrm{~m}$ depth for the submicron droplet concentration of $1 \mathrm{ppm}$. On the other hand, 1 ppm of micrometer-sized Petrobaltic oil droplets caused $73 \%$ $\mathrm{E}_{d}$ drop at 5-10 $\mathrm{m}$ depth below sea surface, while the concentration of 5 ppm resulted in a 99\% decrease of the downwelling light below $4 \mathrm{~m}$ depth in comparison to the natural seawater.

\subsection{Euphotic zone depth}

Petrobaltic oil droplets in seawater reduced the depth of the euphotic zone, $z_{1 \%}(555)$, calculated for the central visible wavelength of $555 \mathrm{~nm}$ (see Table 1). The degree of changes increased with oil concentration as well as with oil penetration depth. Moreover, we noticed that submicron oil droplets had caused greater decrease in the depth of the euphotic zone than micrometer-sized ones. Petrobaltic oil dispersion characterized by the peak diameter of droplet size distribution of $0.3 \mu \mathrm{m}$ and penetration depth of $5 \mathrm{~m}$ showed a potentially detectable reduction in the depth of the euphotic zone of $5.5 \%$ at the concentration of only $10 \mathrm{ppb}$. The concentration of $1 \mathrm{ppm}$ resulted in $77 \%$ reduction of $z_{1 \%}(555)$. On the other hand, the dispersion characterized by the peak diameter of droplet size distribution of $5.0 \mu \mathrm{m}$ gave similar $z_{1 \%}$ (555) reduction by 10 times higher droplet concentrations.

\section{CONCLUSIONS}

Radiative transfer modelling is a great tool to predict optical signatures in underwater light fluxes after oil pollution, as long as the IOPs of natural seawater and dispersed oil are known. The Mie-modelled IOPs of Petrobaltic oil dispersions have been successfully included into presented radiative transfer modelling. The inclusion of spectral-dependent scattering phase function for natural seawater has significantly improved our model accuracy, and therefore we recommend its application in optically complex water basins, such as the Baltic Sea.

Vertical changes of natural sun light within the water body have been analysed, and potential impact on downwelling light from dispersed Petrobaltic crude oil droplets has been
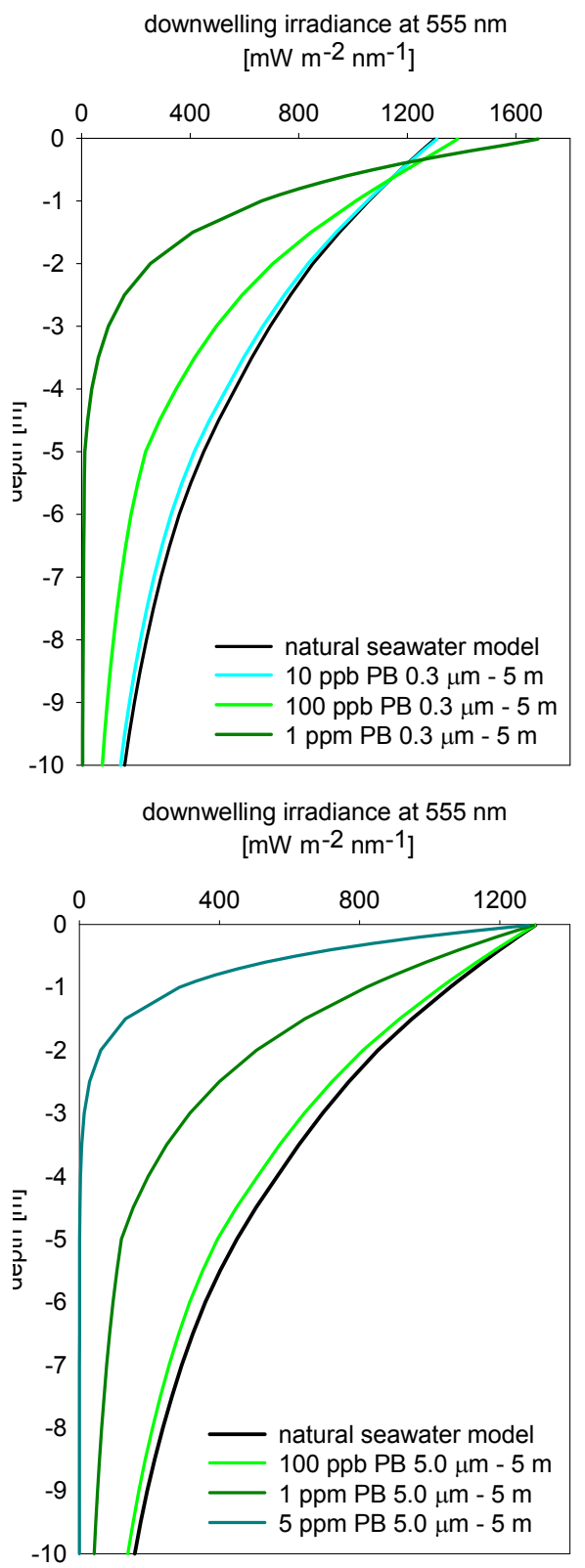

FIG. 9 The influence of oil droplet concentration on downwelling irradiance modelled for seawater polluted by Petrobaltic oil dispersions of droplet size distributions characterized by peak diameter $0.3 \mu \mathrm{m}$ (top graph) and $5.0 \mu \mathrm{m}$ (bottom graph).

demonstrated. Depending on oil concentration and size of oil droplets, dispersed oil can have significant effect on the level and depth profile of the downwelling irradiance. For a typically considered oil concentration of $1 \mathrm{ppm}$, the reduction of downwelling irradiance can reach almost $75 \%$ at $5 \mathrm{~m}$ below sea surface, what in consequence can significantly affect all underwater processes which depend on light availability, like photosynthesis, underwater visibility as well as sunlightinduced vertical heat transfer in the oceans. Dispersed oil has significant impact on all remote sensing applications and op- 
tical parameters derived using remotely sensed methods. We find it worthy to perform such analyses for a wider range of droplet size distributions and different types of oil.

\section{ACKN OWLEDGEMENTS}

The research was funded by the grant of National Science Centre of Poland no. UMO-2012/05/N/ST10/03707. The partial support for this study was also provided by the project "Satellite Monitoring of the Baltic Sea Environment SatBałtyk", founded by European Union through European Regional Development Fund contract no. POIG 01.01.02-22$011 / 09$. The authors are grateful to the colleague from Gdynia Maritime University, dr. Wlodzimierz Freda, and colleagues from the Institute of Oceanology of Polish Academy of Sciences: prof. Jacek Piskozub, prof. Sławomir Sagan and dr. Monika Wozniak for providing some data and valuable comments. The computational part of research was supported by the Academic Computer Centre in Gdansk (CI TASK).

\section{A INHERENT OPTICAL PROPERTIES OF NATURAL SEAWATER}

Tables 2 and 3 show the inherent optical properties of natural seawater measured in the Southern Baltic Sea at a coastal station L4 (N 54.8, E 17.5) on $25^{\text {th }}$ May 2012 using a flow-through absorption-attenuation meter (AC-9, WetLabs).

\begin{tabular}{|c|ccccc|}
\hline $\begin{array}{c}\text { depth } \\
(\mathrm{m})\end{array}$ & $\begin{array}{c}\mathrm{a} 412 \\
\left(\mathrm{~m}^{-1}\right)\end{array}$ & $\begin{array}{c}\mathrm{a} 440 \\
\left(\mathrm{~m}^{-1}\right)\end{array}$ & $\begin{array}{c}\mathrm{a} 488 \\
\left(\mathrm{~m}^{-1}\right)\end{array}$ & $\begin{array}{c}\mathrm{a} 510 \\
\left(\mathrm{~m}^{-1}\right)\end{array}$ & $\begin{array}{c}\mathrm{a} 532 \\
\left(\mathrm{~m}^{-1}\right)\end{array}$ \\
\hline 0 & 0.704 & 0.456 & 0.238 & 0.177 & 0.131 \\
1 & 0.714 & 0.465 & 0.245 & 0.181 & 0.136 \\
2 & 0.724 & 0.472 & 0.249 & 0.186 & 0.139 \\
3 & 0.688 & 0.441 & 0.229 & 0.169 & 0.127 \\
4 & 0.691 & 0.444 & 0.231 & 0.172 & 0.129 \\
5 & 0.751 & 0.495 & 0.263 & 0.194 & 0.146 \\
6 & 0.730 & 0.477 & 0.250 & 0.186 & 0.140 \\
7 & 0.688 & 0.441 & 0.228 & 0.168 & 0.127 \\
8 & 0.689 & 0.441 & 0.227 & 0.167 & 0.126 \\
9 & 0.684 & 0.439 & 0.227 & 0.166 & 0.126 \\
10 & 0.687 & 0.440 & 0.227 & 0.167 & 0.125 \\
11 & 0.686 & 0.443 & 0.228 & 0.166 & 0.126 \\
\hline \hline depth & $\mathrm{a} 555$ & $\mathrm{a} 650$ & $\mathrm{a} 676$ & $\mathrm{a} 715$ & \\
$(\mathrm{~m})$ & $(\mathrm{m}-1)$ & $\left(\mathrm{m}^{-1}\right)$ & $\left(\mathrm{m}^{-1}\right)$ & $\left(\mathrm{m}^{-1}\right)$ & \\
\hline 0 & 0.094 & 0.024 & 0.022 & 0.000 & \\
1 & 0.096 & 0.025 & 0.023 & 0.000 & \\
2 & 0.098 & 0.025 & 0.024 & 0.000 & \\
3 & 0.089 & 0.022 & 0.020 & 0.000 & \\
4 & 0.090 & 0.024 & 0.022 & 0.000 & \\
5 & 0.103 & 0.028 & 0.028 & 0.000 & \\
6 & 0.099 & 0.027 & 0.025 & 0.000 & \\
7 & 0.089 & 0.022 & 0.022 & 0.000 & \\
8 & 0.087 & 0.022 & 0.022 & 0.000 & \\
9 & 0.090 & 0.023 & 0.023 & 0.000 & \\
10 & 0.088 & 0.023 & 0.023 & 0.000 & \\
11 & 0.087 & 0.025 & 0.023 & 0.000 & \\
\hline & & & & & \\
\hline
\end{tabular}

TABLE 2 Values of absorption coefficient in $\mathrm{m}^{-1}$ given for 9 different wavelengths and depths in $\mathrm{m}$, normalized to the pure water.

\begin{tabular}{|c|ccccc|}
\hline $\begin{array}{c}\text { depth } \\
(\mathrm{m})\end{array}$ & $\begin{array}{c}\mathrm{c} 412 \\
\left(\mathrm{~m}^{-1}\right)\end{array}$ & $\begin{array}{c}\mathrm{c} 440 \\
\left(\mathrm{~m}^{-1}\right)\end{array}$ & $\begin{array}{c}\mathrm{c} 488 \\
\left(\mathrm{~m}^{-1}\right)\end{array}$ & $\begin{array}{c}\mathrm{c} 510 \\
\left(\mathrm{~m}^{-1}\right)\end{array}$ & $\begin{array}{c}\mathrm{c} 532 \\
\left(\mathrm{~m}^{-1}\right)\end{array}$ \\
\hline 0 & 1.145 & 0.893 & 0.664 & 0.600 & 0.539 \\
1 & 1.181 & 0.931 & 0.697 & 0.622 & 0.564 \\
2 & 1.229 & 0.973 & 0.735 & 0.669 & 0.606 \\
3 & 1.069 & 0.82 & 0.604 & 0.544 & 0.490 \\
4 & 1.089 & 0.841 & 0.616 & 0.565 & 0.507 \\
5 & 1.356 & 1.090 & 0.836 & 0.759 & 0.690 \\
6 & 1.257 & 0.996 & 0.753 & 0.687 & 0.624 \\
7 & 1.076 & 0.828 & 0.606 & 0.549 & 0.496 \\
8 & 1.076 & 0.825 & 0.610 & 0.548 & 0.495 \\
9 & 1.063 & 0.821 & 0.605 & 0.545 & 0.496 \\
10 & 1.064 & 0.824 & 0.606 & 0.546 & 0.494 \\
11 & 1.071 & 0.830 & 0.608 & 0.548 & 0.497 \\
\hline \hline depth & $\mathrm{c555}$ & $\mathrm{c} 650$ & $\mathrm{c} 676$ & $\mathrm{c} 715$ & \\
$(\mathrm{~m})$ & $(\mathrm{m}-1)$ & $\left(\mathrm{m}^{-1}\right)$ & $\left(\mathrm{m}^{-1}\right)$ & $\left(\mathrm{m}{ }^{-1}\right)$ & \\
\hline 0 & 0.491 & 0.373 & 0.360 & 0.342 & \\
1 & 0.513 & 0.388 & 0.373 & 0.356 & \\
2 & 0.549 & 0.418 & 0.404 & 0.383 & \\
3 & 0.443 & 0.337 & 0.324 & 0.309 & \\
4 & 0.457 & 0.351 & 0.339 & 0.324 & \\
5 & 0.626 & 0.483 & 0.465 & 0.435 & \\
6 & 0.568 & 0.434 & 0.420 & 0.395 & \\
7 & 0.448 & 0.344 & 0.334 & 0.316 & \\
8 & 0.446 & 0.345 & 0.334 & 0.320 & \\
9 & 0.456 & 0.350 & 0.337 & 0.321 & \\
10 & 0.448 & 0.350 & 0.338 & 0.323 & \\
11 & 0.447 & 0.353 & 0.338 & 0.324 & \\
\hline & & & & & \\
\hline
\end{tabular}

TABLE 3 Values of attenuation coefficient in $\mathrm{m}^{-1}$ given for 9 different wavelengths and depths in $\mathrm{m}$, normalized to the pure water.

\section{References}

[1] Z. Lee, K. Du, R. Arnone, S. Liew, and B. Penta, "Penetration of solar radiation in the upper ocean: a numerical model for oceanic and coastal waters," J. Geophys. Res. 110, C002780 (2005).

[2] J. R. V. Zaneveld, J. C. Kitchen, and J. L. Mueller, "Vertical structure of productivity and its vertical integration as derived from remotely sensed observations," Limnol. Oceanogr. 38, 1384-1393 (1993).

[3] G. C. Chang, and T. D. Dickey, "Coastal ocean optical influences on solar transmission and radiant heating rate," J. Geophys. Res. 109, C001821 (2004).

[4] M. R. Lewis, M. Carr, G. Feldman, W. Esaias, and C. McMclain, "Influence of penetrating solar radiation on the heat budget of the equatorial Pacific Ocean," Nature 347, 543-545 (1990).

[5] J. T. 0. Kirk, "Solar heating of water bodies as influenced by their inherent optical properties," J. Geophys. Res. 93, 10897-10908 (1988).

[6] H. G. Stefan, J. J. Cardoni, F. R. Schiebe, and C. M. Cooper, "Model of light penetration in a turbid lake," Water Resour. Res. 19, 109-120 (1983).

[7] N. G. Jerlov, Marine Optics (Elsevier, New York, 1976).

[8] C.-C.Liu, K. L. Carder, R. L. Miller, and J. E. Ivey, "Fast and accurate model of underwater scalar irradiance," Appl. Optics 41, 4962-4974 (2002).

[9] Z. Lee, M. Darecki, K. L. Carder, C. 0. Davis, D. Stramski, and W. J. Rhea, "Diffuse attenuation coefficient of downwelling irra- 
diance: An evaluation of remote sensing methods," J. Geophys. Res. 110, (2005).

[10] C. D. Mobley, Light and water: radiative transfer in natural waters (Elsevier, New York, 1994).

[11] J. T. 0. Kirk, Light and Photosynthesis in Aquatic Ecosystems (Cambridge University Press, New York, 1994).

[12] Z. Lee, A. Weidemann, J. Kindle, R. Arnone, K. L. Carder, and C. Davis, "Euphotic zone depth: its derivation and implication to ocean-color remote sensing," J. Geophys. Res. 112, C003802 (2007).

[13] G. D. Baffico, "Optical properties and light penetration in a deep, naturally acidic, iron rich lake: Lago Caviahue (Patagonia, Argentina)," Limnologica 43, 475-481 (2013).

[14] C. L. Gallegos, and T. E. Jordan, "Impact of the spring 2000 phytoplankton bloom in Chesapeake bay on optical properties and light penetration in the Rhode river, Maryland," Estuaries 25, 508-518 (2002).

[15] A. Morel, and S. Maritorena, "Bio-optical properties of oceanic waters: a reappraisal," J. Geophys. Res. 106, 1763-7180 (2001).

[16] F. R. Pick, "The abundance and composition of freshwater picocyanobacteria in relation to light penetration," Limnol. Oceanogr. 36, 1457-1462 (1991).

[17] A. Bricaud, A. Morel, and L. Prieur, "Absorption by dissolved organic matter of the sea (yellow substance) in the UV and visible domains," Limnol. Oceanogr. 26, 45-53 (1981).

[18] S. B. Wozniak, D. Stramski, “Modeling the optical properties of mineral particles suspended in seawater and their influence on ocean reflectance and chlorophyll estimation from remote sensing algorithms," Appl. Optics 43, 3489-3503 (2004).

[19] M. Babin, and D. Stramski, "Variations in the mass-specific absorption coefficient of mineral particles suspended in water," Limnol. Oceanogr. 49, 756-767 (2004).

[20] D. Stramski, and J. Tegowski, "Effects of intermittent entrainment of air bubbles by breaking wind waves on ocean reflectance and underwater light field," J. Geophys. Res. 106, C000461 (2001).

[21] A. Stelmaszewski, T. Krol, and H. Toczek, "Light scattering in Baltic crude oil-seawater emulsion," Oceanologia 51, 405-414 (2009).

[22] National Research Council, Oil in the sea III: inputs, fates, and effects (The National Academies Press, Washington D. C., 2003).

[23] M. Fingas, Oil spill science and technology (Elsevier, Amsterdam, 2011).

[24] Y. Gong, X. Zhao, Z. Cai, S. E. O'Reilly, X. Hao, and D. Zhao, “A review of oil, dispersed oil and sediment interactions in the aquatic environment: Influence on the fate, transport and remediation of oil spills," Mar. Pol. Bul. 79, 16-33 (2014).

[25] K. Rudz, M. Darecki, and H. Toczek, "Modelling the influence of oil content on optical properties of seawater in the Baltic Sea," J. Eur. Opt. Soc.-Rapid. 8, 13063 (2013).
[26] W. Freda, and J. Piskozub, "Improved method of FournierForand marine phase function parameterization," Opt. Express 15 , 12763-12768 (2007).

[27] C. D. Mobley, L. K. Sundman, and E. Boss, "Phase function effects on oceanic light fields," Appl. Optics 41, 1035-1050 (2002).

[28] W. Freda, "Comparison of the spectral-angular properties of light scattered in the Baltic Sea and oil emulsions," J. Eur. Opt. Soc.Rapid. 9, 14017 (2014).

[29] 0. Johansen, P. J. Brandvik, and U. Farooq, “Droplet breakup in subsea oil releases, Part 2: Predictions of droplet size distributions with and without injection of chemical dispersants," Mar. Pollut. Bull. 73, 327-335 (2013).

[30] Z. Li, K. Lee, T. King, H. Niu, M. C. Boufadel, A. D. Venosa, “Application of entropy analysis of in situ droplet-size spectra in evaluation of oil chemical dispersion efficacy," Mar. Pollut. Bull. 62, 2129-2136 (2011).

[31] M. Jonasz, and G. R. Fournier, Light scattering by particles in water: theoretical and experimental foundations (Academic Press, San Diego, 2007).

[32] Z. Otremba, "Oil droplets as light absorbents in seawater," Opt. Express 15, 8592-8597 (2007).

[33] G. A. L. Delvigne, and C. E. Sweeney, "Natural dispersion of oil," Oil Chem. Pollut. 4, 281-310 (1988).

[34] Z. Li, K. Lee, T. King, M. C. Boufadel, and A. D. Venosa, “Evaluating crude oil chemical dispersion efficacy in a flow-through wave tank under regular non-breaking wave and breaking wave conditions," Mar. Pollut. Bull. 58, 735-744 (2009).

[35] C. F. Bohren, and D. R. Huffman, Absorption and scattering of light by small particles (John Wiley at Sons, New York, 1983).

[36] V. Drozdowska, W. Freda, E. Baszanowska, K. Rudz, M. Darecki, J. R. Heldt, and H. Toczek, "Spectral properties of natural and oil polluted Baltic seawater - results of measurements and modelling," Eur. Phys. J.- Spec. Top. 222, 2157-2170 (2013).

[37] W. Freda, "Spectral dependence of the correlation between the backscattering coefficient and the volume scattering function measured in the southern Baltic Sea," Oceanologia 54, 355-367 (2012).

[38] T. J. Petzold, Volume scattering functions for selected ocean waters (Scripps Institute of Oceanography, University of California, San Diego, 1972).

[39] W. Freda, and J. Piskozub, "Revisiting the role of oceanic phase function in remote sensing reflectance," Oceanologia 54, 29-38 (2012). 